\title{
BEBERAPA IDENTITAS BARISAN FIBONACCI DAN LUCAS
}

\section{IDENTITIES OF FIBONACCI AND LUCAS SEQUENCES}

\author{
Mira Mustika ${ }^{\mathrm{a}}$, Wamiliana ${ }^{\mathrm{b}}$ \\ ${ }^{\text {a }}$ Program Studi Matematika Institut Teknologi Sumatera \\ Jalan Terusan Ryacudu, Desa Way Hui, Jati Agung, Lampung Selatan, \\ mira.mustika@ma.itera.ac.id \\ b Jurusan Matematika Universitas Lampung \\ Jalan Soemantri Brojonegoro, No.1, Bandar Lampung, \\ wamiliana.1963@fmipa.unila.ac.id ${ }^{2}$
}

\begin{abstract}
Abstrak
Penelitian ini bertujuan untuk menyelidiki hubungan antara barisan Fibonacci dan Lucas, dan membuktikan identitas-identitas barisan Fibonacci dan Lucas. Barisan Fibonacci dan Lucas merupakan barisan rekursif yang mempunyai aturan yang sama namun memiliki nilai awal yang berbeda. Dalam penelitian ini, akan dibahas beberapa identitas yang melibatkan kedua barisan tersebut, serta satu identitas yang berkaitan dengan segitiga Pascal.

Kata kunci : Barisan Fibonacci, barisan Lucas, relasi, idetitas barisan.

\section{Abstract}

This study aims to investigate the relations between the Fibonacci dan Lucas sequences and prove the identities of the Fibonacci and Lucas sequences. Fibonacci and Lucas sequences are recursive sequences with the same rules but have different initial values. In this paper some identities involving those two sequences will be discussed, including one identity that relates with the Pascal triangle.
\end{abstract}

Keywords : Fibonacci sequence, Lucas sequence, relations, sequence identity.

\section{Pendahuluan}

Sejak tahun 2009, terdapat materi baru untuk seleksi masuk perguruan tinggi negeri, yaitu TPA (Tes Potensi Akademik). Salah satu jenis soal pada TPA adalah tes angka. Tes angka bertujuan untuk mengukur kemampuan angka dalam kaitannya dengan kemampuan berpikir secara terstruktur dan logis matematis (Tim Grad 2010). Pada tes angka ini, sering dijumpai soalsoal yang erat kaitannya dengan pola bilangan, barisan maupun deret.

Barisan merupakan fungsi yang didefinisikan pada himpunan bilangan asli $\mathbb{N}=\{1,2,3, \ldots\}$ yang daerah hasilnya termuat dalam himpunan bilangan Riil $\mathbb{R}$ (Bartle dan Sherbert 2011). 
Misalkan $\quad x_{0}, x_{1}, x_{2}, \ldots, x_{n}, \ldots$ dinotasikan sebagai barisan bilangan. $x_{n}$ disebut juga sebagai bentuk umum dari barisan (Brualdi 2009).

Barisan dapat dinyatakan setidaknya dalam tiga cara. Pertama, didefinisikan dengan memberikan formula umum (rumusan eksplisit) unsur ke- $n$. Sebagai contoh, $x_{n}=\frac{1}{n}$ mendefinisikan barisan di mana unsur ke$n$ adalah $\frac{1}{n}$. Kedua, didefinisikan dengan memberikan relasi rekursif $x_{n+1}=$ $f\left(x_{n}, x_{n-1}, \ldots, x_{1}\right)$. Misalnya, diberikan suatu barisan $x_{n+1}=\frac{2}{x_{n}}$ dengan $x_{1}=1$. Dalam menyatakan barisan dengan relasi rekursi perlu diberikan nilai awal $\left(x_{0}\right.$ atau $\left.x_{1}\right)$ agar barisan terdefinisi tunggal. Ketiga, barisan dapat didefinisikan dengan memberikan daftar parsialnya $\left(x_{n}\right)=x_{1}, x_{2}, \ldots, x_{n}$ (Neswan 2018).

Ada dua macam barisan yang cukup dikenal yaitu barisan aritmetika dan barisan geometri. Barisan aritmetika memiliki sifat yaitu setiap suku memiliki selisih yang sama dengan suku sebelumnya. Sedangkan suku-suku pada barisan geometri memiliki kelipatan yang sama dari suku sebelumnya. Selain itu terdapat suatu barisan yang memiliki keunikan lain yaitu barisan Fibonacci dan barisan Lucas (Brualdi 2009).
Fibonacci adalah seorang matematikawan asal Italia yang hidup pada abad 12. Latar belakang munculnya barisan Fibonacci adalah untuk menggambarkan pertumbuhan sepasang kelinci selama setahun. Misalkan pertumbuhan jumlah kelinci mengikuti keadaan sebagai berikut: Sepasang kelinci (satu betina dan satu jantan) menjadi dewasa dalam waktu dua bulan, dan setiap bulan berikutnya berturut-turut melahirkan sepasang anak kelinci, jantan dan betina. Bila tidak ada kelinci yang mati, bagaimanakah perkembangan jumlah pasangan kelinci itu pada setiap awal bulan?

Pada bulan pertama dan kedua terdapat satu pasang kelinci. Pada bulan ketiga bertambah satu menjadi tiga pasang kelinci. Pada bulan keempat, dua pasang kelinci melahirkan sehingga menjadi lima pasang kelinci, dan seterusnya. Banyaknya pasangan kelinci setiap awal bulan berturut-turut terlihat pada barisan di bawah ini :

$$
1,1,2,3,5,8,13,21 \ldots
$$

Barisan di atas disebut barisan Fibonacci.

Fibonacci sendiri tidak banyak menyelidiki lebih lanjut mengenai masalah yang ia kemukakan tersebut. Ia pun tidak memberikan nama barisannya sebagai barisan Fibonacci. Nama barisan Fibonacci baru muncul pada abad ke-19 yang diperkenalkan oleh matematikawan 
asal Perancis yang bernama Lucas. Lucas mengembangkan suatu barisan yang mempunyai sifat seperti barisan Fibonacci yang kemudian disebut barisan Lucas, yaitu sebagai berikut :

$$
2,1,3,4,7,11,18, \ldots .
$$

Barisan Fibonacci dan Lucas merupakan barisan yang didefinisikan secara relasi rekursif yaitu $x_{n+2}=$ $x_{n+1}+x_{n}, n \in \mathbb{N}$. Misal $F_{n}, L_{n}$ masingmasing menyatakan rumus umum untuk barisan Fibonacci dan Lucas, nilai awal untuk barisan Fibonacci adalah $F_{0}=$ $1, F_{1}=1$ dan nilai awal untuk barisan Lucas adalah $L_{0}=2, L_{1}=1$. Untuk menentukan suku ke- $n$ dari barisan Fibonacci dan Lucas dapat menggunakan formula Binet. Formula Binet untuk barisan Fibonacci diberikan sebagai berikut:

$$
F_{n}=\frac{\alpha^{n}-\beta^{n}}{\alpha-\beta} \cdot n=1,2,3, \ldots
$$

dengan $\alpha=\frac{1+\sqrt{5}}{2}$, dan $\beta=\frac{1-\sqrt{5}}{2}$. Dari formula Binet di atas diperoleh $F_{0}=$ $1, F_{1}=1, F_{2}=1$ dan seterusnya.

Sedangkan formula Binet untuk barisan Lucas dinyatakan sebagai:

$$
L_{n}=\alpha^{n}+\beta^{n}, n=1,2,3, \ldots
$$

dengan $L_{0}=2, L_{1}=1, L_{2}=3$ dan seterusnya. (Datta dan Mahajan 2014).

Tujuan dari penelitian ini adalah menyelidiki hubungan (relasi) dari barisan Fibonacci dan Lucas, serta mengidentifikasi identitas-identitas barisan Fibonacci dan Lucas.

\section{Metode Penelitian}

Metode yang digunakan pada penelitian ini adalah kajian literatur, seperti buku-buku penunjang, internet dan jurnal yang berhubungan dengan barisan Fibonacci dan Lucas. Adapun langkah-langkah yang dilakukan dalam penelitian ini adalah sebagai berikut.

1. Mengumpulkan dan mempelajari pustaka-pustaka yang berkaitan dengan penelitian.

2. Mencari dan menemukan relasi (hubungan) antara barisan Fibonacci dan Lucas.

3. Menentukan dan membuktikan identitas dari barisan Fibonacci dan Lucas.

Untuk membuktikan identitas barisan Fibonacci dan Lucas digunakan beberapa metode yaitu pembuktian langsung dan Induksi Matematika. Pada pembuktian langsung, diasumsikan hipotesa benar, selanjutnya dengan langkah-langkah yang logis maka kesimpulan dapat diperoleh. Pada Prinsip Induksi Matematika, diberikan $P(n)$ merupakan pernyataan mengenai bilangan asli $n$. Misal, (a) $P(1)$ benar dan (b) untuk tiap $k \in \mathbb{N}$, jika $P(k)$ benar 
maka $P(k+1)$ benar. Dapat disimpulkan bahwa $P(n)$ benar untuk setiap $n \in \mathbb{N}$ (Neswan 2018).

Langkah-langkah penelitian ini dapat digambarkan dalam diagram alir sebagai berikut.

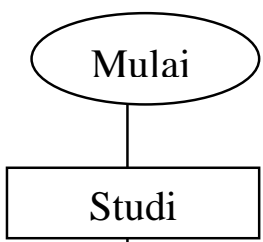

Menentukan relasi antara barisan Fibonacci dan Lucas

Membuktikan identitas barisan

Diperoleh identitas barisan Fibonacci dan Lucas

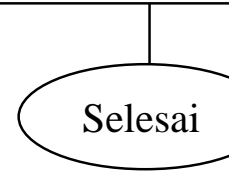

Gambar 1. Diagram Alir Penelitian

\section{Hasil Dan Pembahasan}

Barisan Fibonacci dan Lucas mempunyai kesamaan yaitu suku ke $-\mathrm{n}$ dari barisan tersebut didapat dengan menjumlahkan tepat dua suku sebelumnya. Perbedaannya terletak dari nilai awal masing - masing barisan. Kesamaan yang dimiliki dapat menjadi salah satu sebab adanya hubungan dari kedua barisan tersebut sehingga membentuk suatu identitas.

Perhatikan tabel berikut sebagai gambaran untuk melihat relasi pertama antara barisan Fibonacci dan Lucas.

Tabel 1. Identitas Barisan Fibonacci dan Lucas Pertama

\begin{tabular}{|l|l|l|l|l|l|l|l|l|l|l|}
\hline $\mathrm{n}$ & 0 & 1 & 2 & 3 & 4 & 5 & 6 & 7 & 8 & 9 \\
\hline Fn & 0 & 1 & 1 & 2 & 3 & 5 & 8 & 13 & 21 & 34 \\
\hline Ln & 2 & 1 & 3 & 4 & 7 & 11 & 18 & 29 & 47 & 76 \\
\hline
\end{tabular}

Dari sembilan suku pertama barisan Fibonacci dan Lucas di atas, dengan pola yang terbentuk tampak ada hubungan antara kedua barisan tersebut, yaitu:

\section{Teorema 1.}

Untuk barisan Fibonacci $\left(F_{n}\right)$ dan Lucas $\left(L_{n}\right)$ diperoleh hubungan:

$$
F_{n-1}+F_{n+1}=L_{n} ; n \geq 1
$$

Bukti : Dengan menerapkan formula Binet untuk barisan Fibonacci dan Lucas, diperoleh:

$$
\begin{aligned}
F_{n-1}+F_{n+1}= & \frac{\alpha^{n-1}-\beta^{n-1}}{\alpha-\beta}+ \\
& \frac{\alpha^{n+1}-\beta^{n+1}}{\alpha-\beta} \\
= & \frac{\alpha^{n}\left(\alpha+\alpha^{-1}\right)}{\alpha-\beta}- \\
& \frac{\beta^{n}\left(\beta+\beta^{-1}\right)}{\alpha-\beta}
\end{aligned}
$$




$$
F_{n-1}+F_{n+1}=\alpha^{n}+\beta^{n}=L_{n}
$$

Karena $\frac{\left(\alpha+\alpha^{-1}\right)}{\alpha-\beta}=1$ dan $\frac{\left(\beta+\beta^{-1}\right)}{\alpha-\beta}=-1$ diperoleh:

$$
F_{n-1}+F_{n+1}=\alpha^{n}+\beta^{n}=L_{n}
$$

Tabel 3. Identitas Barisan Fibonacci dan Lucas Ketiga

Tabel 2. Identitas Barisan Fibonacci dan Lucas Kedua

\begin{tabular}{|l|l|l|l|l|l|l|l|l|l|}
\hline $\mathrm{n}$ & 0 & 1 & 2 & 3 & 4 & 5 & 6 & 7 & $\cdots$ \\
\hline Fn & 0 & 1 & 1 & 2 & 3 & 5 & 8 & 13 & $\cdots$ \\
\hline Ln & 2 & 1 & 3 & 4 & 7 & 11 & 18 & 29 & $\cdots$ \\
\hline
\end{tabular}

Perhatikan kolom-kolom dengan warna yang sama. Secara umum akan berlaku relasi barisan Fibonacci dan Lucas berikut.

\section{Teorema 2.}

Untuk barisan Fibonacci $\left(F_{n}\right)$ dan Lucas $\left(L_{n}\right)$ diperoleh hubungan:

$$
F_{n+2}-F_{n-2}=L_{n} ; n \geq 2
$$

Bukti : Dengan menerapkan formula Binet untuk barisan Fibonacci dan Lucas, diperoleh:

$$
\begin{aligned}
F_{n+2}-F_{n-2}= & \frac{\alpha^{n+2}-\beta^{n+2}}{\alpha-\beta}-\frac{\alpha^{n-2}-\beta^{n-2}}{\alpha-\beta} \\
= & \frac{\alpha^{n}\left(\alpha^{2}-\alpha^{-2}\right)}{\alpha-\beta}- \\
& \frac{\beta^{n}\left(\beta^{2}-\beta^{-2}\right)}{\alpha-\beta}
\end{aligned}
$$

Karena $\frac{\left(\alpha^{2}-\alpha^{-2}\right)}{\alpha-\beta}=1$ dan $\frac{\left(\beta^{2}-\beta^{-2}\right)}{\alpha-\beta}=-1$

diperoleh: 
Selain tiga relasi di atas, berikut diberikan teorema yang menyatakan relasi antara barisan Fibonacci dan Lucas.

Teorema 4. Untuk setiap bilangan asli $n$, diperoleh relasi barisan Fibonacci dan Lucas berikut.

$$
F_{n} \times L_{n}=F_{2 n} ; n \geq 1
$$

Bukti :

$$
\begin{aligned}
F_{n} x L_{n} & =\left(\frac{\alpha^{n}-\beta^{n}}{\alpha-\beta}\right)\left(\alpha^{n}+\beta^{n}\right) \\
& =\left(\frac{\alpha^{2 n}-\beta^{2 n}}{\alpha-\beta}\right)=F_{2 n}
\end{aligned}
$$

Teorema 5. Untuk setiap bilangan asli $n$ dengan $n \geq 2$ diperoleh relasi barisan Fibonacci dan Lucas berikut.

$$
\begin{gathered}
F_{2^{n}}=L_{2^{0}} \times L_{2^{1}} \times L_{2^{2}} \times \ldots \times L_{2^{n-1}} ; \\
n \geq 1, n \text { bilangan Asli. }
\end{gathered}
$$

Bukti : Dalam membuktikan teorema 5 di atas menggunakan metode pembuktian dengan Prinsip Induksi Matematika.

a) Misal, $P(n)$ menyatakan bahwa $F_{2^{n}}=$ $L_{2^{0}} \times L_{2^{1}} \times L_{2^{2}} \times \ldots \times L_{2^{n-1}} \quad$ untuk $n \geq 1$.

b) Basis induksi. Jelas bahwa $P(1)$ benar. Dengan kata lain $F_{2}=L_{1}$

c) Langkah induksi. Anggap bahwa $P(k)$ benar. Dengan kata lain, $F_{2^{k}}=$
$L_{2^{0}} \times L_{2^{1}} \times L_{2^{2}} \times \ldots \times L_{2^{k-1}}$

dianggap pernyataan yang benar.

Selanjutnya akan dibuktikan bahwa $P(k+1)$ benar.

$$
F_{2^{k+1}}=F_{2.2^{k}}
$$

Berdasarkan Teorema 4, diperoleh:

$$
F_{2^{k+1}}=F_{2.2^{k}}=F_{2^{k}} L_{2^{k}}
$$

$$
\leftrightarrow F_{2^{k+1}}=L_{2^{0}} \times L_{2^{1}} \times L_{2^{2}} \times \ldots \times L_{2^{k-1}}
$$$$
\times L_{2^{k}}
$$

\section{Barisan Fibonacci pada Segitiga Pascal}

Segitiga Pascal dapat dituliskan dengan formula:

$$
a_{n r}=\frac{n !}{(n-r) ! r !}=\left(\begin{array}{l}
n \\
r
\end{array}\right)
$$

dengan $a_{n r}$ menyatakan entri pada baris ke- $n$ dan kolom ke- $k$, serta $\left(\begin{array}{l}n \\ r\end{array}\right)$ merupakan koefisien binomial. Entri $a_{00}=\left(\begin{array}{l}0 \\ 0\end{array}\right)=1$ menyatakan entri pada baris teratas.

Formula Pascal menujukkan bahwa setiap baris berikutnya didapat dengan menambahkan dua entri diagonal di atasnya.

Dari Gambar 2 dan 3, diperoleh hubungan bahwa penjumlahan angka pada tiap diagonal di segitiga Pascal akan menghasilkan barisan Fibonacci, dan 
dapat dinyatakan dengan formula sebagai berikut.

\section{Teorema 6.}

$$
\sum_{k=0}^{\left\lfloor\frac{n}{2}\right\rfloor}\left(\begin{array}{c}
n-k \\
k
\end{array}\right)=F_{n+1} ; n=0,1,2, \ldots
$$

$n$ menyatakan bilangan bulat non-negatif, $\left\lfloor\frac{n}{2}\right\rfloor$ menyatakan bilangan bulat terbesar yang nilainya lebih kecil atau sama dengan $\frac{\boldsymbol{n}}{\mathbf{2}}$.

Formula di atas dapat dibuktikan dengan menggunakan Prinsip Induksi Matematika.

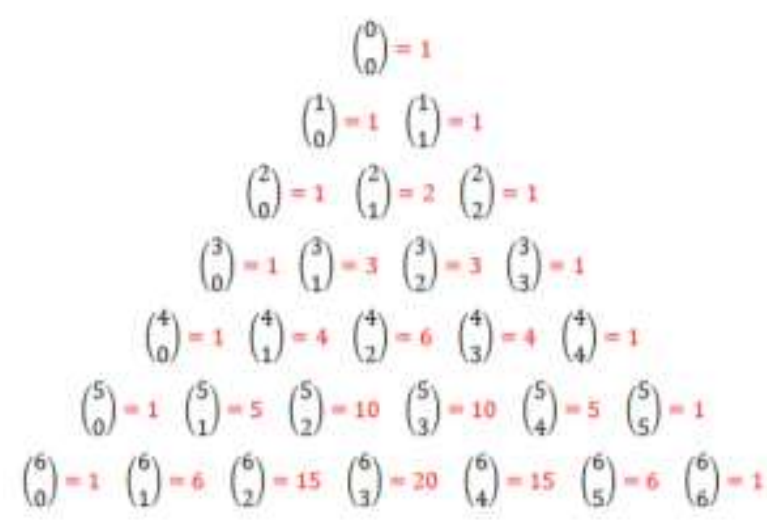

Gambar 2. Segitiga Pascal

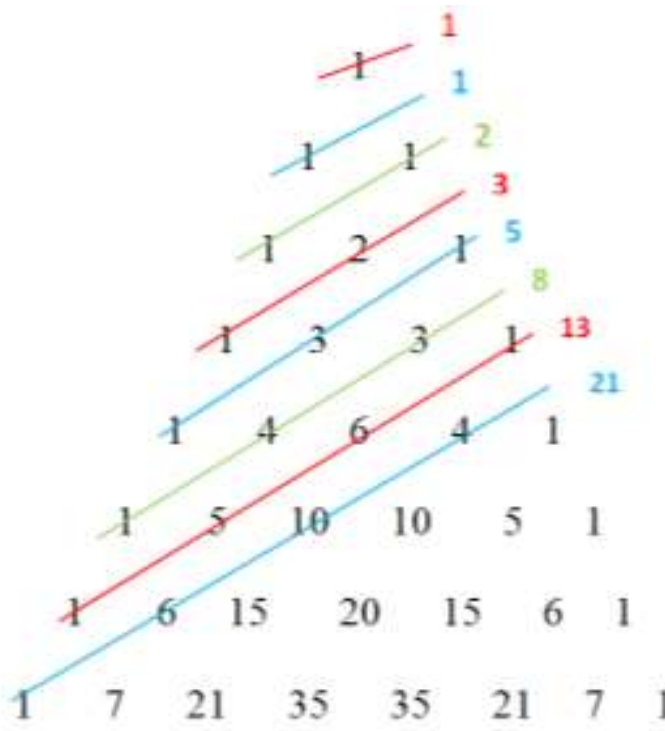

Gambar 3. Segitiga Pascal dan Barisan Fibonacci

\section{Kesimpulan}

Kesimpulan dari hasil dan pembahasan di atas adalah:

1. Terdapat relasi/hubungan antara barisan Fibonacci dan Lucas.

2. Beberapa relasi dari barisan Fibonacci dan Lucas antara lain sebagai berikut:
a. $F_{n-1}+F_{n+1}=L_{n} ; n \geq 1$
b. $F_{n+2}-F_{n-2}=L_{n} ; n \geq 2$
c. $F_{n+3}+F_{n-3}=2 L_{n} ; ; n \geq 3$
d. $F_{n} \times L_{n}=F_{2 n} ; n \geq 1$
e. $F_{2^{n}}=L_{2^{1}} \times L_{2^{2}} \times L_{2^{3}} \times \ldots \times$
$L_{2^{n-1}} ; n \geq 1$
dengan $n$ merupakan anggota bilangan Asli.

3. Barisan Fibonacci dapat ditemukan juga dalam segitiga Pascal, yaitu 
penjumlahan angka pada tiap diagonal dari segitiga Pascal akan membentuk barisan Fibonacci. Secara umum dapat ditulis:

$$
\begin{gathered}
\sum_{k=0}^{\left\lfloor\frac{n}{2}\right\rfloor}\left(\begin{array}{c}
n-k \\
k
\end{array}\right)=F_{n+1} \\
n=0,1,2, \ldots
\end{gathered}
$$

Saran yang dapat disampaikan pada penelitian ini adalah untuk penelitian selanjutnya, tidak menutup kemungkinan masih banyaknya relasi yang akan didapatkan antara barisan Fibonacci dan Lucas. Untuk membuktikan relasi-relasi tersebut dapat digunakan metode pembuktian langsung, kontradiksi, maupun dengan menggunakan Prinsip Induksi Matematika.

\section{Pustaka}

Bartle, R.G., Sherbert,D.R. (2011). Introduction to Real Analysis Fourth Edition. John Wiley \& Sons,Inc.

Brualdi, R.A. (2009). Introductory Combinatorics, Fifth Edition. China Machine Press.

Datta, S., Mahajan, M. (2014). The Binet Forms for the Fibonacci and Lucas Numbers. International Journal of Mathematics Trends and Technology.10(1), 14-16.

Neswan, O. (2018). Analisis Real Elementer. Bandung : ITB Press.

Tim Grad. 2010. Cara Mudah Lulus TPA. Gradien Mediatama, Yogyakarta. 